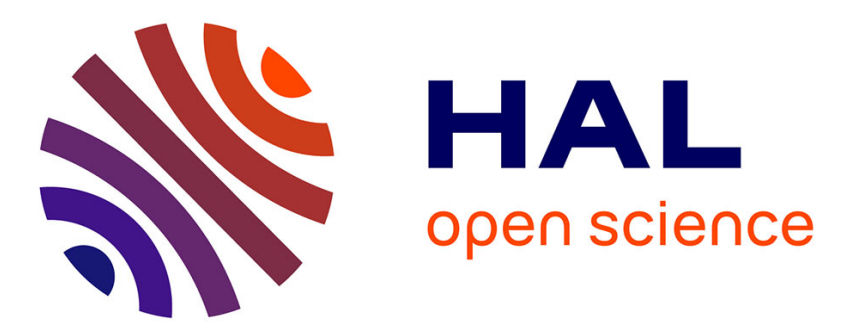

\title{
Correlation between mechanical and microstructural properties of molybdenum nitride thin films deposited on silicon by reactive $\mathrm{RF}$ magnetron discharge
}

Boudjemaa Bouaouina, Aurélien Besnard, Seddik El Hak Abaidia, Aissam Airoudj, Fayçal Bensouici

\section{To cite this version:}

Boudjemaa Bouaouina, Aurélien Besnard, Seddik El Hak Abaidia, Aissam Airoudj, Fayçal Bensouici. Correlation between mechanical and microstructural properties of molybdenum nitride thin films deposited on silicon by reactive RF magnetron discharge. Surface and Coatings Technology, 2018, 333, pp.32-38. 10.1016/j.surfcoat.2017.10.028 . hal-01728041

\section{HAL Id: hal-01728041 \\ https://hal.science/hal-01728041}

Submitted on 9 Mar 2018

HAL is a multi-disciplinary open access archive for the deposit and dissemination of scientific research documents, whether they are published or not. The documents may come from teaching and research institutions in France or abroad, or from public or private research centers.
L'archive ouverte pluridisciplinaire HAL, est destinée au dépôt et à la diffusion de documents scientifiques de niveau recherche, publiés ou non, émanant des établissements d'enseignement et de recherche français ou étrangers, des laboratoires publics ou privés. 


\title{
Correlation between mechanical and microstructural properties of molybdenum nitride thin films deposited on silicon by reactive R.F. magnetron discharge
}

\author{
B. Bouaouina ${ }^{\mathrm{a}, *}$, A. Besnard $^{\mathrm{b}}$, S.E. Abaidia ${ }^{\mathrm{a}}$, A. Airoudj ${ }^{\mathrm{c}}$, F. Bensouici ${ }^{\mathrm{a}}$ \\ ${ }^{a}$ Department of Physics, Research Unite UR-MPE, Boumerdes University, 35000, Algeria \\ ${ }^{\mathrm{b}}$ Arts et Metiers Paris Tech - LaBoMaP, 71250 Cluny, France \\ c Institut de Sciences des Matériaux de Mulhouse (IS2M), UHA, CNRS, Université de Strasbourg, UMR 7361, 15 rue Jean Starcky, 68057 Mulhouse Cedex, France
}

\section{A R T I C L E I N F O}

\section{Keywords:}

Molybdenum nitride

Microstructure

Nanoindentation

AFM

Residual stress

\begin{abstract}
A B S T R A C T
Molybdenum nitride thin films were deposited on (100) silicon substrates by R.F. magnetron sputtering of a Mo target in a $\left(\mathrm{Ar}-\mathrm{N}_{2}\right)$ gas mixtures. The films were studied by Scanning Electron Microscopy (SEM), Energy Dispersive Spectroscopy (EDS) and X-ray diffraction. The nanomechanical properties have been determined by nanoindentation and Peak-Force Quantitative Nanomechanical Mapping (PF-QNM). The total internal stresses were determined by curvature measurements and the Stoney formula.

As thin film composition influences the morphology, the stress state and the mechanical properties, modifications are expected in this study where the nitrogen content is tuned. The film exhibits a polycrystalline structure with preferred orientation along (111) plane. The increase of the nitrogen content in the coating (N/ Mo $=1.1$ ) induces a broadening of the full width at half maximum (FWHM) of the (111) diffraction peak, which is attributed to the presence of smaller crystallites. The residual stress and mechanical properties variation were correlated to the structural transition from $\gamma-\mathrm{Mo}_{2} \mathrm{~N}$ to hexagonal and cubic MoN. The results show a good agreement between the nanomechanical properties obtained by nanoindentation and PF-QNM.
\end{abstract}

\section{Introduction}

Transition metal nitride thin films have been widely applied to microelectronic, opto-electronic, anti-wear and anti-corrosion coating. Many studies were focused on titanium and chromium nitride as protective coatings [1-5]. Due to their mechanical stability Mo-N coatings make a good candidate for wear resistant coatings in tribological applications [6]. Mo-N thin films were also considered for wear protective coatings [7] and as diffusion barriers for aluminum in ultra-large-scale integrated circuits (ULSI) [8]. Various techniques are used to deposit Mo-N coatings [9], vacuum-arc evaporation [10], plasma-enhanced chemical vapor deposition (PECVD) [11], cathodic arc PVD [6] and nitride layers by ion implantation [12]. And among these techniques, DC and R.F. magnetron sputtering are the most versatile processes allowing deposition of films with high quality even at low substrate temperatures [9]. The equilibrium phase diagram of molybdenum-nitrogen proposed by Jehn [13], enriched by computed phases of nonstoichiometric transition metal nitrides $\mathrm{Mo}_{3} \mathrm{~N}_{2}$ [14], shows three stable phases: the tetragonal $\beta-\mathrm{Mo}_{2} \mathrm{~N}$ phase at low temperature, the cubic $\gamma$ $\mathrm{Mo}_{2} \mathrm{~N}$ phase stable at high temperature and the hexagonal $\delta$-MoN phase up to 50 at.\% nitrogen concentration. Using non-equilibrium processes, the phase structure of Mo-N coatings depends on the deposition technology, and mainly on the pressure of nitrogen in the working chamber and the substrate bias voltage [15]. Ihara et al. report also on the existence of a cubic $\zeta$-MoN phase [16]. While this phase is thermodynamically unstable, a stabilization can be achieved using non-equilibrium techniques such as R.F. sputtering in high nitrogen partial pressure, nitrogen ion implantation, or low energy ion assisted deposition $[17,18]$. The mechanical properties of the molybdenum nitride coatings are firmly dependant on the nitrogen pressure in reactive sputtering [19]. The $\zeta$-MoN phase is predicted to have the highest superconducting temperature among all refractory binary carbides and nitrides with $\mathrm{T}_{\mathrm{c}}=29.4 \mathrm{~K}$ [20]. However, a narrow set of parameters provide an incomplete and misleading results, so more information about the material structure and applicability can be gained by mechanical testing [21].

This paper reports on structural and mechanical properties of molybdenum nitride thin films grown by R.F. magnetron sputtering in a $\left(\mathrm{Ar}-\mathrm{N}_{2}\right)$ gas mixture. The aim is to contribute to the understanding of the influence of nitrogen addition to the plasma on the film properties.

\footnotetext{
* * Corresponding author.

E-mail address: b.bouaouina@gmail.com (B. Bouaouina).
} 
We have investigated the effect of the nitrogen partial pressure on the microstructure and different physical properties of Mo-N films. A correlation between the changes observed and the phase transition is examined.

\section{Experimental}

Molybdenum nitride films were deposited by R.F. (13.56 MHz) reactive magnetron sputtering in an NORDIKO 3500 system as described in a previous paper [22]. The target is a $100 \mathrm{~mm}$ diameter disk of pure molybdenum (purity 99.98 at.\%). The chamber is pumped down via a cryogenic pump backed by a primary pump, allowing a residual vacuum of about $10^{-7}$ mbar. Argon (working gas) and nitrogen (reactive gas) were introduced into the chamber through a mass flow controller, while the absolute working pressure was fixed at $5 \times 10^{-3} \mathrm{mbar}$. The gas pressure was measured using a BOC EDWARDS gauge. The nitrogen partial pressures reach values of $20 \%, 30 \%, 40 \%$ and $50 \%$ of the absolute working pressure. The target to substrate distance was about $170 \mathrm{~mm}$ with an angle of $30^{\circ}$, with respect to the substrate normal. The R.F. power density on the cathode was fixed at $3.18 \mathrm{~W} \cdot \mathrm{cm}^{-2}$, with the R.F. voltage on the target fixed at $800 \mathrm{~V}$. All depositions were performed at room temperature.

Before the deposition process, the Si substrates were cleaned in an ultrasonic bath, first with acetone then ethanol solutions, dried and kept at room temperature. The target was cleaned by ion etching for 2 min in an argon plasma discharge.

The film thickness was determined by step measurements using an optical profilometer (Wyko NT 1100), which was also used to obtain a topographic image of the substrate before and after coating for the stress calculations. The values and directions of the principal radii of curvature were obtained by Gwyddion. The film structure was examined by X-ray diffraction (XRD) using a Bruker D8 diffractometer operating in Bragg-Brentano $\theta / 2 \theta$ configuration using a $\mathrm{Cu} \mathrm{K} \alpha$ wavelength (1.5406 $\AA$ ), the scan was performed in two angle ranges of $2 \theta$, from $32^{\circ}$ to $69^{\circ}$ and $72^{\circ}$ to $90^{\circ}$ to avoid the intense diffraction peak of Si substrate at $2 \theta=69.13^{\circ}$. Scanning Electron Microscopy (JEOL JSM$5900 \mathrm{LV}$ ) was used to analyze the microstructure and to confirm the film thickness by cross-section images. The chemical composition of the films was obtained by energy dispersive X-ray spectroscopy. Indentation and recording of force-displacement curves were performed on a CSM Nano Instrument Berkovich Indenter. The elastic modulus was calculated from the unloading part of load-penetration curves using the standard Oliver-Pharr method. Elastic modulus and hardness values were obtained by an average of five measurement runs. AFM measurements were carried out in a Bruker Multimode IV, with a Nanoscope V controller and an E "vertical" scanner, by the Peak Force Quantitative Nanomechanical Mapping (PF-QNM ${ }^{\circledR}$, Bruker) method. $\mathrm{PF}-\mathrm{QNM}$ is a contact AFM mode, based on the force-volume method. In this type of method, force distance curves are collected by nanoindentation of the sample in a point-by-point mode. The maximum force (peak force) is controlled at each pixel to obtain force-distance curves which are then used as feedback signal. In this method, the loading and unloading force-distance curves are collected at a frequency of $2 \mathrm{kHz}$ at each position within the mapped area of the specimen. In parallel to topography images, information on material elasticity (Young's modulus), deformation and tip-to-surface adhesion force were obtained. The modulus distribution for each sample surface was then plotted and fitted with a modified exponential Gaussian law; the reported moduli thus correspond to the center of the distributions whereas the errors correspond to their widths. All measurements were made in air and at room temperature. $1 \mu \mathrm{m} \times 1 \mu \mathrm{m}(256 \times 256$ pixels at $0.8 \mathrm{~Hz}$ ) scans were taken at three different locations on the sample surface. The peak-force set-point was adjusted to $200 \mathrm{nN}$ and the Poisson's ratio was assumed to be equal to 0.3 . Mechanical properties of the cantilever, as well as tip geometry must be taken into consideration when performing PF-QNM measurements in order to get relevant

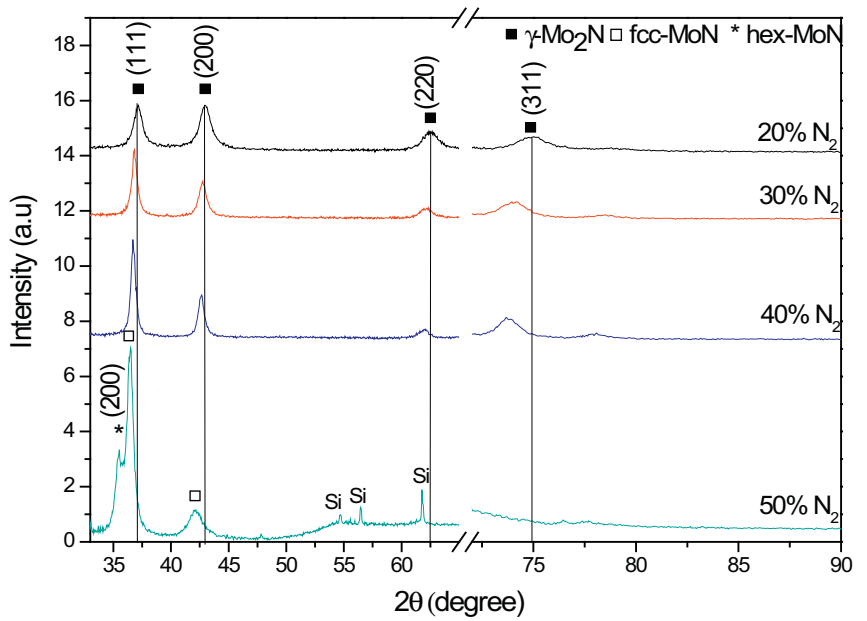

Fig. 1. XRD spectra for Mo-N layers deposited on Si substrate as a function of the partial pressure of nitrogen in plasma: $20 \% \mathrm{~N}_{2}, 30 \% \mathrm{~N}_{2}, 40 \% \mathrm{~N}_{2}$, and $50 \% \mathrm{~N}_{2}$, at a working pressure of $5 \times 10^{-3} \mathrm{mbar}$.

results. All quantitative measurements were carried out with DNISP-HS cantilevers (Bruker, USA) with a spring constant of $350 \mathrm{~N} / \mathrm{m}$ and resonance frequency of $50 \mathrm{kHz}$. The deflection sensitivity measured on fused silica and the actual cantilever spring constant was measured by the thermal tune method [23] and found to be around $260 \mathrm{~N} / \mathrm{m}$. Tip radius was calibrated against a polystyrene standard provided by Bruker. The measured value of the tip radius was $35 \mathrm{~nm}$. Between two measurements, the probes were recalibrated on the first measured sample, in order to take into account the wear of the tip, by adjusting the tip radius value.

\section{Results and discussion}

\subsection{Structural properties}

Fig. 1 shows the X-ray diffraction spectra with a Bragg-Brentano $\theta$ / $2 \theta$ configuration of molybdenum nitride thin films deposited at different nitrogen partial pressure on silicon substrate. All the deposited films are polycrystalline. The films obtained with $10^{-3}$ to $2 \times 10^{-3}$ mbar nitrogen partial pressure $\left(20 \%, 30 \%\right.$ and $\left.40 \% \mathrm{~N}_{2}\right)$ present diffraction peaks observed at $2 \theta=37.1^{\circ}, 42.8^{\circ}, 62.3^{\circ}$ and $74.8^{\circ}$, corresponding to the (111), (200), (220) and (311) planes, respectively, in cubic structure. Taking into account the standard reference sample listed in (00-025-1366) PDF database, the films can be assigned to the $\gamma-\mathrm{Mo}_{2} \mathrm{~N}$ phase in cubic structure with a lattice parameter of $4.194 \AA$ [24]. The lattice parameter of the films calculated from the diffraction plane (111), ranged between $4.194 \AA$ and $4.266 \AA$. The crystal structure of the $\gamma-\mathrm{Mo}_{2} \mathrm{~N}$ synthesized at room temperature, is NaCl-like where the Mo atoms occupy the positions of the fcc lattice points and nitrogen atoms occupy $50 \%$ of the total octahedral sites [25].

Increasing the nitrogen pressure in the plasma causes a preferred orientation of crystal growth along (111) direction, a shift of the diffraction peak at low angle and a narrowing of the full width at half maximum (FWHM) values.

At $2.5 \times 10^{-3}$ mbar nitrogen partial pressure (50\% nitrogen concentration), two overlapping peaks were observed at $2 \theta=35.6^{\circ}, 36.4^{\circ}$ and a small peak at $2 \theta=42^{\circ}$ corresponding to the hexagonal MoN (200), cubic (111) and (200) planes respectively. However, the number of peaks was changed, which indicates a change in the crystalline phase of $\gamma-\mathrm{Mo}_{2} \mathrm{~N}$, something that could be assigned to the formation of hexagonal MoN and the B1-MoN phases [16,26]. The B1-MoN phase is also known as cubic metastable $\zeta$-MoN phase $[9,27,28]$. The XRD pattern exhibits weak peaks at $2 \theta=47.8^{\circ}, 54.7^{\circ}$ and $56.4^{\circ}$, which correspond to undesirable polychromatic substrate reflections. The peak at 
$2 \theta=61.7^{\circ}$ is associated to the $\mathrm{Si}$ substrate reflection of the $\mathrm{Cu} \mathrm{K}_{\beta}$ (1.3922 ̊) line.

Previous studies report the elastic instability of B1-MoN structure [29]. Koutná et al. [30] have reported that the $\mathrm{Mo}_{0.91} \mathrm{~N}\left(\mathrm{MoN}_{1.09}\right)$ structure is more stable than the perfect phase by ab initio calculations. Similar result has been found with first principles calculations, that indicate that the cubic $\mathrm{MoN}_{\mathrm{x}}$ with $0.54<\mathrm{x}<1.3$ is the most stable when containing both anion and cation vacancies [31]. Donovan and Hubler [32] have produced the metastable B1-MoN by electron beam evaporation deposition of molybdenum with simultaneous bombardment by nitrogen ions.

In a previous study of Inumaru et al. [33], the preparation of the crystallized stoichiometric and nitrogen-deficient B1-MoN films by pulsed laser deposition is reported. On the other hand, Stöber et al. reported that at $50 \%$ nitrogen content the Mo-N thin form crystallite sizes of $6.4 \mathrm{~nm}$ and a more pronounced texture of the $\gamma-\mathrm{Mo}_{2} \mathrm{~N}$ structure [34]. Saito and Asada have reported a phase change from the cubic $\gamma$ $\mathrm{Mo}_{2} \mathrm{~N}$ to a B1-type MoN by increasing the $\mathrm{N}_{2}{ }^{+}$ions implanted in sputtered Mo thin films at room temperature [35]. Others [6,36,37] reported the existence of a mixed phase of cubic $\gamma-\mathrm{Mo}_{2} \mathrm{~N}$ and hexagonal $\delta$-MoN crystalline structure as the nitrogen concentration increases in the plasma. Some others observed the crystalline $\gamma-\mathrm{Mo}_{2} \mathrm{~N}$ phase in their films and when the nitrogen concentration increased to $50 \%$ the transition to an amorphous structure is reported [38]. Anitha [25] has found that $\gamma-\mathrm{Mo}_{2} \mathrm{~N}$ is the only phase present as the nitrogen concentration increases.

In the present study, $\gamma-\mathrm{Mo}_{2} \mathrm{~N}$ is indeed the only phase present as the nitrogen concentration increases from $20 \%$ to $40 \%$ in the plasma. Under high nitrogen content environments, excessive number of octahedral sites could also be occupied by nitrogen atoms, resulting in an increase of the $\gamma-\mathrm{Mo}_{2} \mathrm{~N}$ lattice parameters as well as a reduction of the $\gamma$ $\mathrm{Mo}_{2} \mathrm{~N}$ structure stability. But, at $50 \%$ nitrogen concentration in the plasma and therefore high nitrogen content in the film, the coexistence of two phases $\delta$-MoN and metastable B1-MoN were observed with hexagonal and cubic structures respectively. Increase of nitrogen content in the film induces a disappearance of the (220), (311) diffraction peaks and an increase of the FWHM of (111) the diffraction peak, which is attributed to the presence of smaller crystallites. Levy et al. have found that the low stability of the cubic MoN phase is related to the electron occupancy of the valence band as determined using XPS technique [39]. The diffraction lines are shifted to lower angles indicating stress in the films. This shift in the peaks of $\gamma-\mathrm{Mo}_{2} \mathrm{~N}$ cubic phase is already reported by several researchers [27,34]. The estimation of the crystallite size in the films is determined using the Debye Scherrer formula [40].

$\mathrm{D}_{\mathrm{hkl}}=\frac{0.89 \lambda}{\beta \cos (\theta)}$

where $D_{\text {hkl }}$ is the crystallite size, $\lambda$ is the $\mathrm{X}$-ray wavelength $1.5406 \AA \mathrm{Cu}$, $\beta$ is full width at half-maximum (FWHM) and $\theta$ is the angle reflection of (111) direction. The crystallite sizes of all films are relatively small in comparison to the values of other transition metal compounds such as TiN, TiC and CrN $[25,41]$, having a grain size in the range $9-18 \mathrm{~nm}$ depending on the nitrogen partial pressure. The calculated grain sizes and the lattice parameters from (111) diffraction peak are shown in Fig. 2.

It is observed that the lattice parameter increases as the N/Mo ratio in the film increases, while the crystallite size firstly increases from 9.2 to $18 \mathrm{~nm}$ and significantly decreases to $12 \mathrm{~nm}$ at $50 \%$ nitrogen concentration. The increase of the lattice parameter and the crystallite size with an increasing nitrogen fraction is due to the incorporation of nitrogen atoms in the otherwise unfilled octahedral interstitial sites $[25,39]$. While the stress is strongly dependent on the grain size [1], its changes could be expected and correlated with the crystallite size evolution (see Section 3.4).

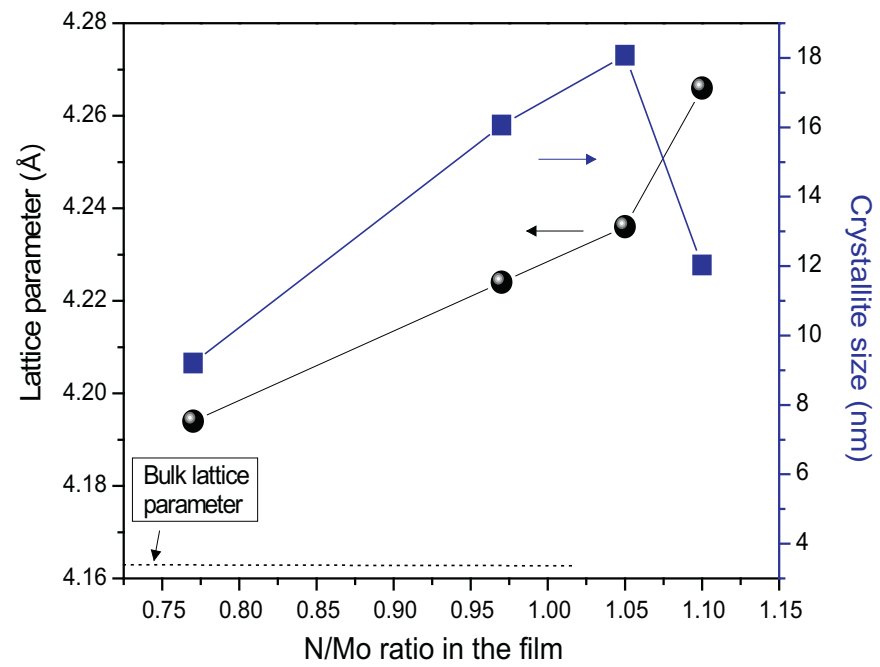

Fig. 2. Crystallite size and lattice parameter as a function of N/Mo ratio in the films at $5 \times 10^{-3}$ mbar working pressure and $3.18 \mathrm{~W} \cdot \mathrm{cm}^{-2}$ power density.

Table 1

Elemental concentration and grain sizes of Mo-N thin films deposited under different nitrogen partial pressure.

\begin{tabular}{|c|c|c|c|c|c|c|}
\hline \multirow{2}{*}{$\begin{array}{l}\text { Nitrogen partial } \\
\text { pressure in the } \\
\text { plasma (mbar) }\end{array}$} & \multicolumn{3}{|c|}{ Content at.\% } & \multirow{2}{*}{$\begin{array}{l}\mathrm{N} / \mathrm{Mo} \\
\text { ratio }\end{array}$} & \multirow[t]{2}{*}{ Thickness $(\mu \mathrm{m})$} & \multirow{2}{*}{$\begin{array}{l}\text { Crystalline } \\
\text { size (nm) }\end{array}$} \\
\hline & Mo & $\mathrm{N}$ & $\mathrm{O}$ & & & \\
\hline $1 \times 10^{-3}$ & 54.6 & 42 & 3.4 & 0.77 & 1.35 & 9.6 \\
\hline $1.5 \times 10^{-3}$ & 47.4 & 46.3 & 6.4 & 0.97 & 1.20 & 11.1 \\
\hline $2 \times 10^{-3}$ & 46.9 & 49.3 & 3.9 & 1.05 & 1.12 & 13.6 \\
\hline $2.5 \times 10^{-3}$ & 45.8 & 50.5 & 3.7 & 1.10 & 0.98 & 8.4 \\
\hline
\end{tabular}
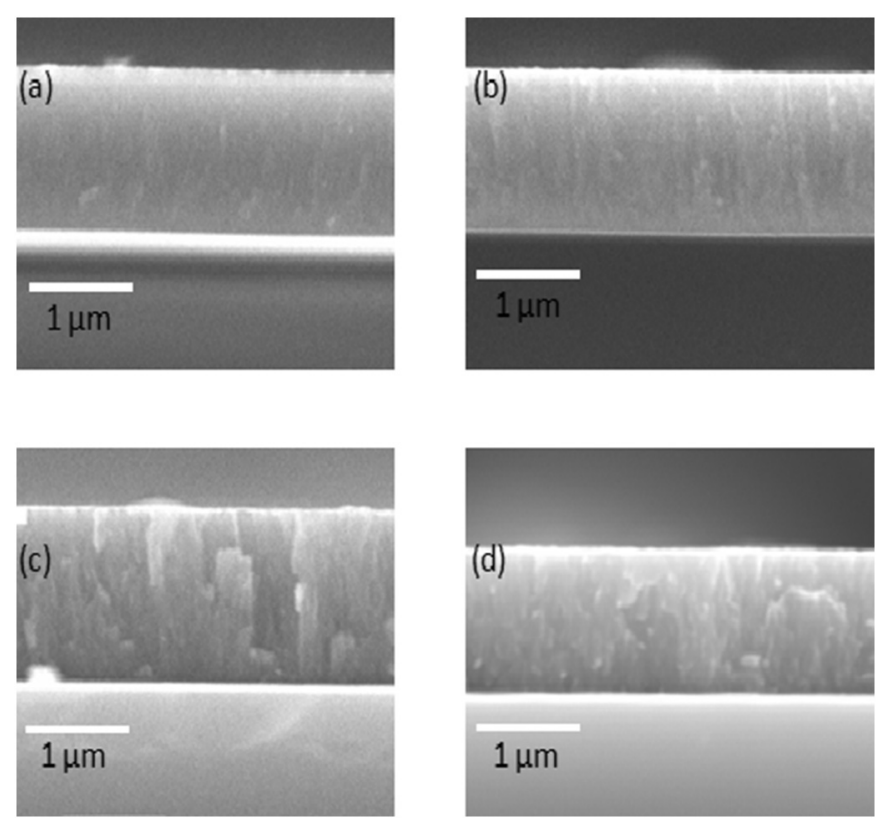

Fig. 3. SEM cross-section images of Mo-N films at different nitrogen partial pressure (a) $10^{-3} \mathrm{mbar}$, (b) $1.5 \times 10^{-3} \mathrm{mbar}$, (c) $2 \times 10^{-3} \mathrm{mbar}$, (d) $2.5 \times 10^{-3} \mathrm{mbar}$.

\subsection{Films composition}

The concentration of molybdenum and nitrogen in the films, estimated from the EDS spectra, is presented in Table 1. In all films, a low content of oxygen is found as impurities. The increase of the nitrogen partial pressure in the chamber induced a decrease in the atomic 


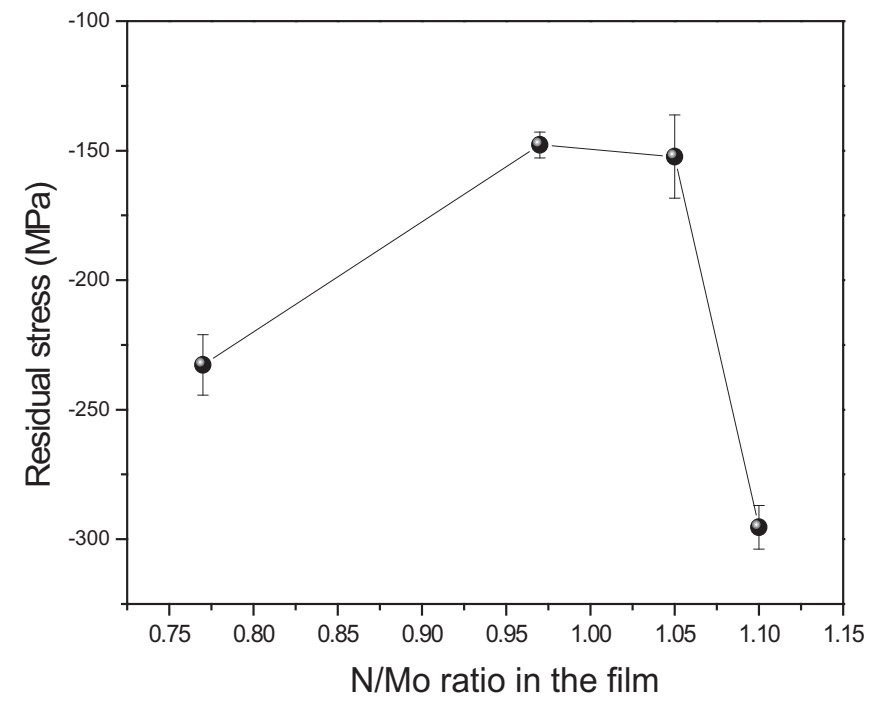

Fig. 4. Residual stress as a function of N/Mo ratio in the films at $5 \times 10^{-3} \mathrm{mbar}$ of working pressure and $3.18 \mathrm{~W} \cdot \mathrm{cm}^{-2}$ power density.

percentage of molybdenum in the films, mostly attributed to the formation of compound layer MoN on the target surface due to the phenomena of target poisoning. The films presented here were prepared in $20 \%-50 \%$ nitrogen content in the plasma and have nitrogen content into the film in the range of 0.77 to 1.10 . When the nitrogen partial pressure increased during the deposition, the ratio N/Mo also increased in the film. The atomic ratio N/Mo into the films obtained is higher than the N/Mo ratio in $\gamma-\mathrm{Mo}_{2} \mathrm{~N}$ structure (0.5), this indicates incorporation of excess nitrogen in the otherwise unfilled octahedral interstitial sites of the $\gamma-\mathrm{Mo}_{2} \mathrm{~N}$ structure [25,38]. In recent studies of Mo$\mathrm{N}$ films [42], $\gamma-\mathrm{MoN}_{\mathrm{x}}$ phase was prepared with nitrogen partial pressure to total pressure ratios, $\mathrm{P}_{\mathrm{N} 2} / \mathrm{P}_{\mathrm{T}}$ between 0.2 and 0.32 with the content of nitrogen in $\gamma-\mathrm{MoN}_{\mathrm{x}}$ phases in the range of $\mathrm{x}=0.30-0.53$ and crystallized in single-phase cubic-structure. The critical nitrogen concentrations for the Mo to $\gamma-\mathrm{Mo}_{2} \mathrm{~N}$ phase transition varied from author to author $[38,43]$. Ozsdolay et al. [31] have deposited $\mathrm{MoN}_{\mathrm{x}} / \mathrm{MgO}(001)$ at different temperatures in the range $600{ }^{\circ} \mathrm{C}$ to $1000{ }^{\circ} \mathrm{C}$, and the N/Mo ratio decreased when the temperature increased from 1.25 to 0.69 and reported a cubic rock-salt type structure.

\subsection{Growth morphology}

Fig. 3 shows SEM cross-section images of Mo-N films on Si substrates. The film at $20 \%$ of nitrogen partial pressure has the denser morphology and presents a smoother surface than the others Fig. 3(a). A columnar structure with distinctive dense areas and rough surface were observed when the nitrogen partial pressure increases Fig. 3(b). The coating prepared at $2 \times 10^{-3}$ mbar has a columnar microstructure Fig. 3(c). A tilt of about $10^{\circ}$ is observed for coatings (c) and (d), probably due to the target inclination. This is consistent with the working pressure and the target inclination angle [22,44]. This tilt is not seen for the other films, due to the fracture direction of the silicon substrate certainly orthogonal to the column tilt ones. The film observed in Fig. 3(d) has a dense columnar structure and less thickness than the other films, which is consistent with the decrease of the sputtering yield. The target surface was poisoned and the compound formation results in a decreased target erosion rate $[45,46]$.

\subsection{Mechanical properties}

\subsubsection{Determination of residual stress}

Residual stress consists of thermal stress originating by the difference in the substrate and the coating thermal expansion coefficients, and the intrinsic stress caused by ion bombardment, lattice mismatch and chemical reactions of the layer $[47,48]$. The residual stress in the thin films was calculated using the Stoney equation [49,50]:

$\sigma=\frac{E_{S}}{6\left(1-v_{s}\right)} \frac{h_{s}^{2}}{h_{f}}\left(\frac{1}{R}\right)$

where $E_{s}$ is the substrate's Young modulus, $\nu_{s}$ the substrate's Poisson ratio, $h_{s}$ is the substrate's thickness, $h_{f}$ the thickness of the film and $R$ the radius of curvature of the film after initial curvature correction. The extraction of the principal directions radii is performed by the "Gwyddion software" from the subtraction of the substrate images before and after deposition. The residual stress in the films at different $\mathrm{N} /$ Mo ratios is presented in Fig. 4.

In all films, a compressive stress state is observed. From 0.77 to $0.97 \mathrm{~N} /$ Mo ratios, the compressive residual stress decreases of about $85 \mathrm{MPa}$. With a small increase in nitrogen content in the film (N/
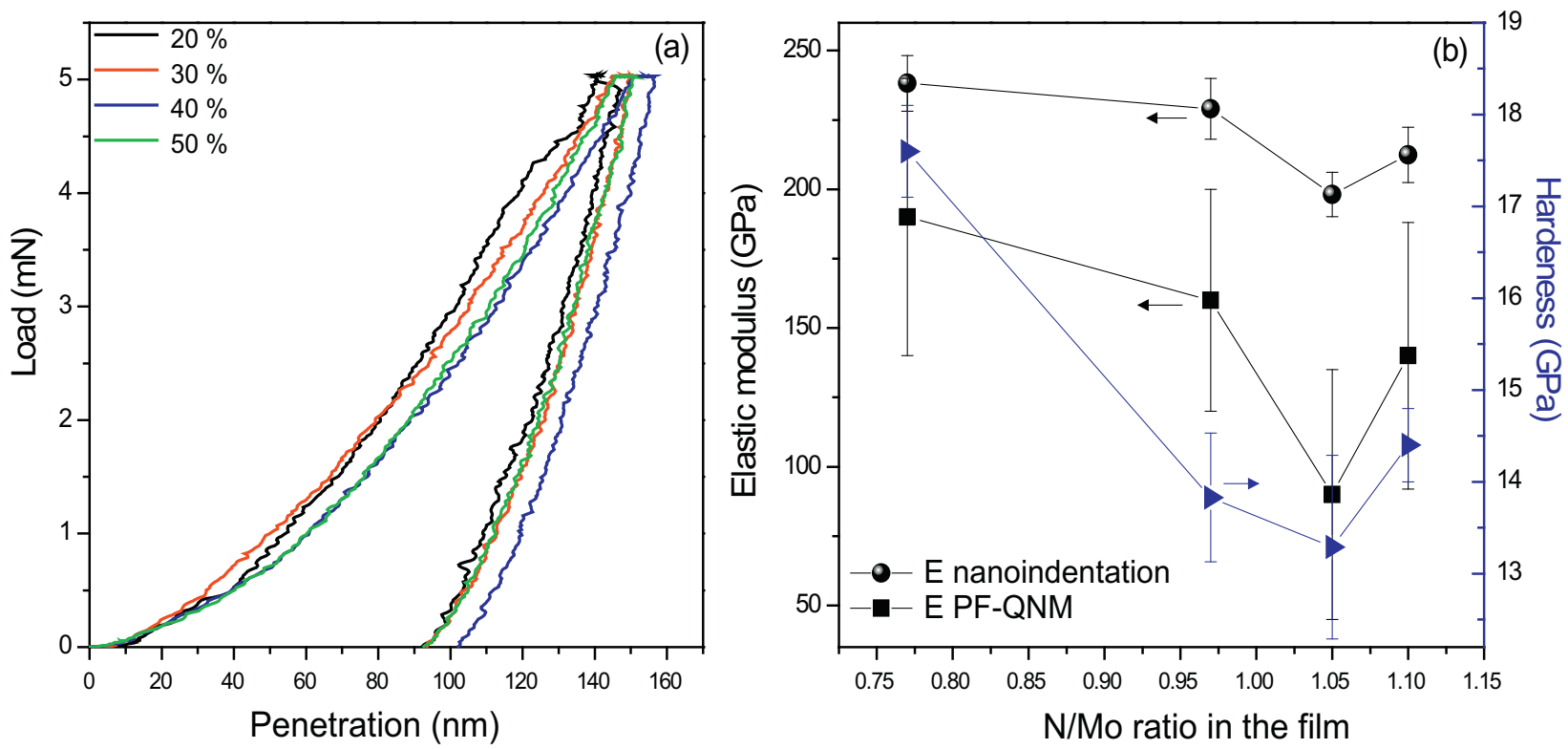

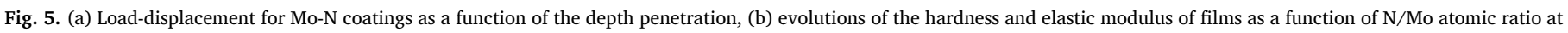
$5 \times 10^{-3}$ mbar of working pressure and $3.18 \mathrm{~W} \cdot \mathrm{cm}^{-2}$ power density by nanoindentation and PF-QNM measurements. 

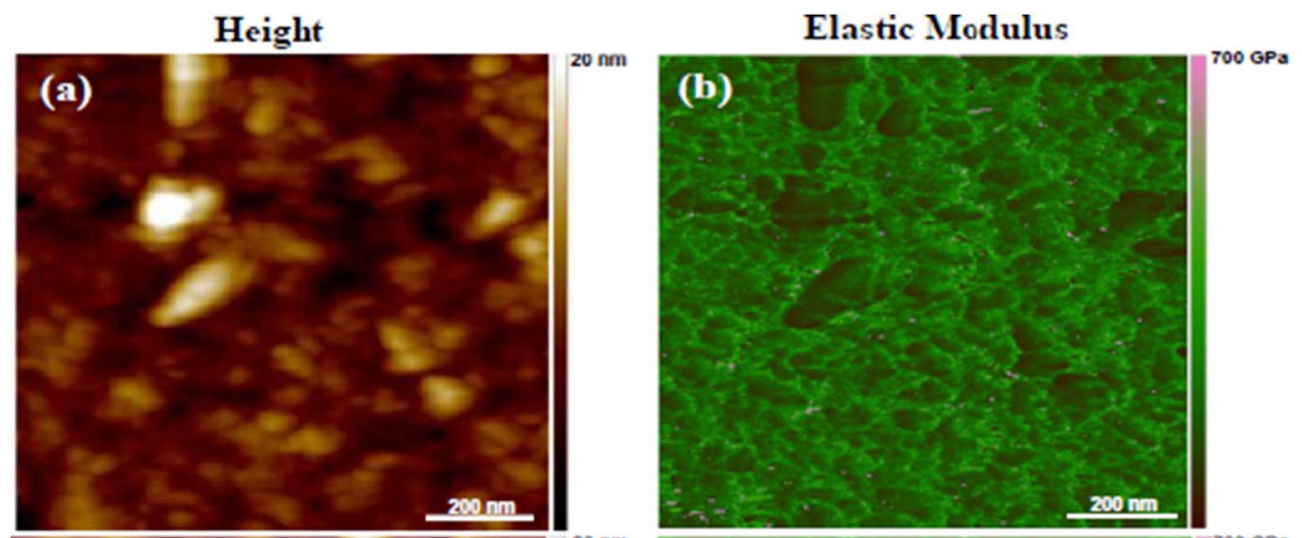

Fig. 6. Representative maps of topography $(1 \mu \mathrm{m} \times 1 \mu \mathrm{m})$ and DMT modulus $(1 \mu \mathrm{m} \times 1 \mu \mathrm{m})$ of samples at $20 \% \mathrm{~N}_{2}$ ((a) and (b)), $30 \% \mathrm{~N}_{2}$ ((c) and (d)), $40 \% \mathrm{~N}_{2}$ ((e) and (f)) and $50 \% \mathrm{~N}_{2}(\mathrm{~g})$ and $\left.(\mathrm{h})\right)$ obtained with Peak Force QNM. The height color scale represents the height from 0 to $20 \mathrm{~nm}$. The DMT modulus color scale represents the modulus from 0 to $700 \mathrm{GPa}$. (For interpretation of the references to color in this figure legend, the reader is referred to the web version of this article.)

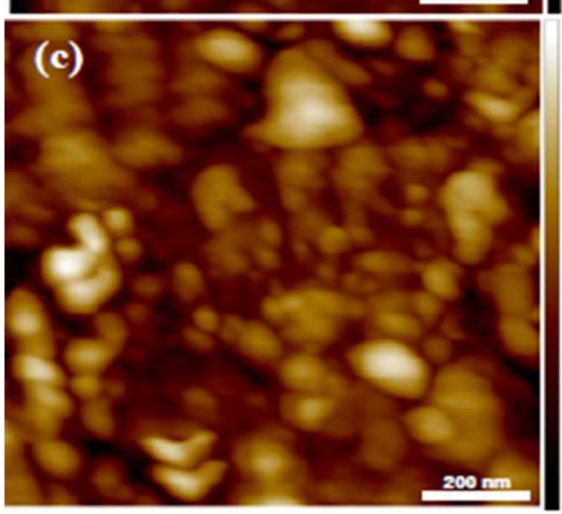

$20 \mathrm{~nm}$
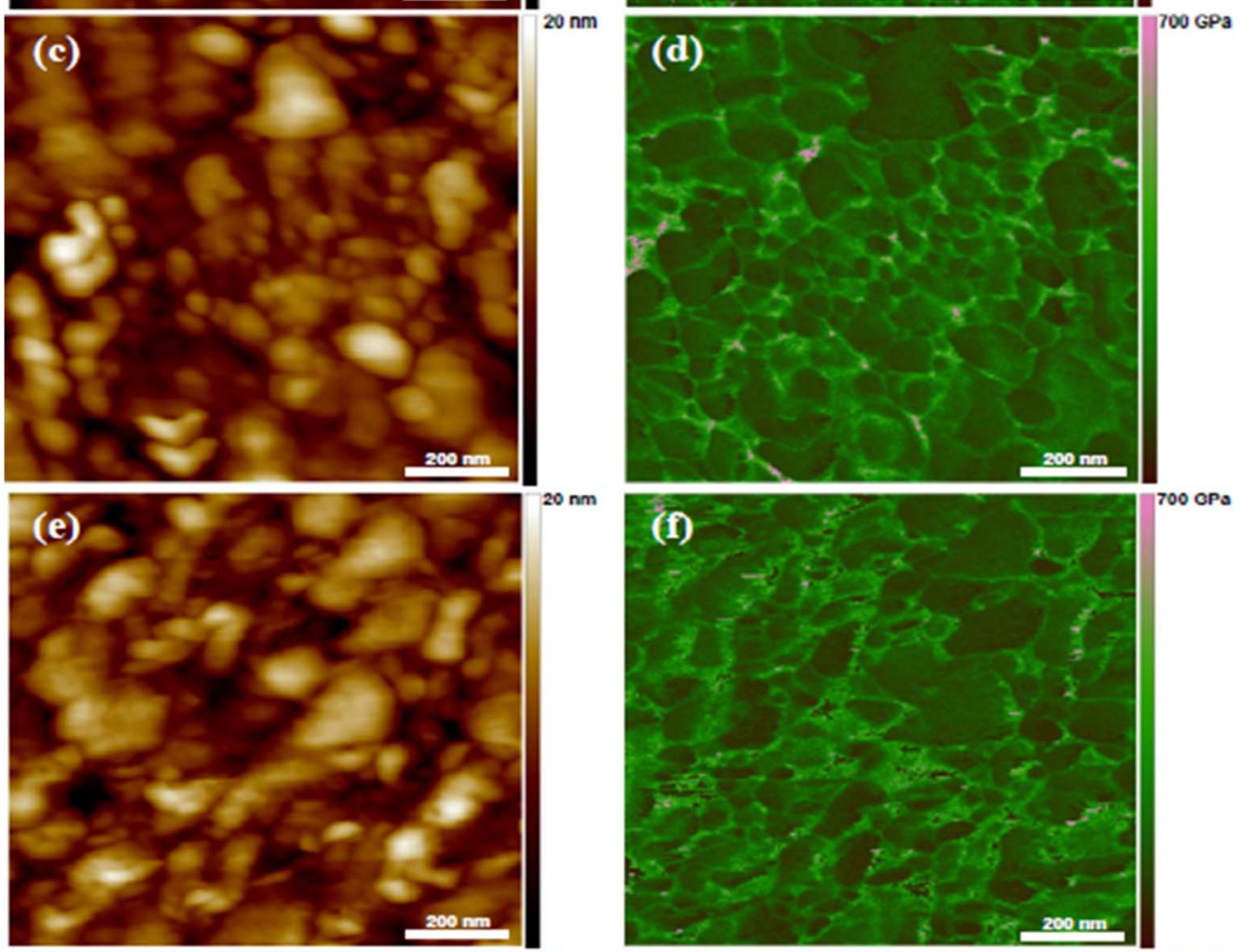

$20 \mathrm{~nm}$
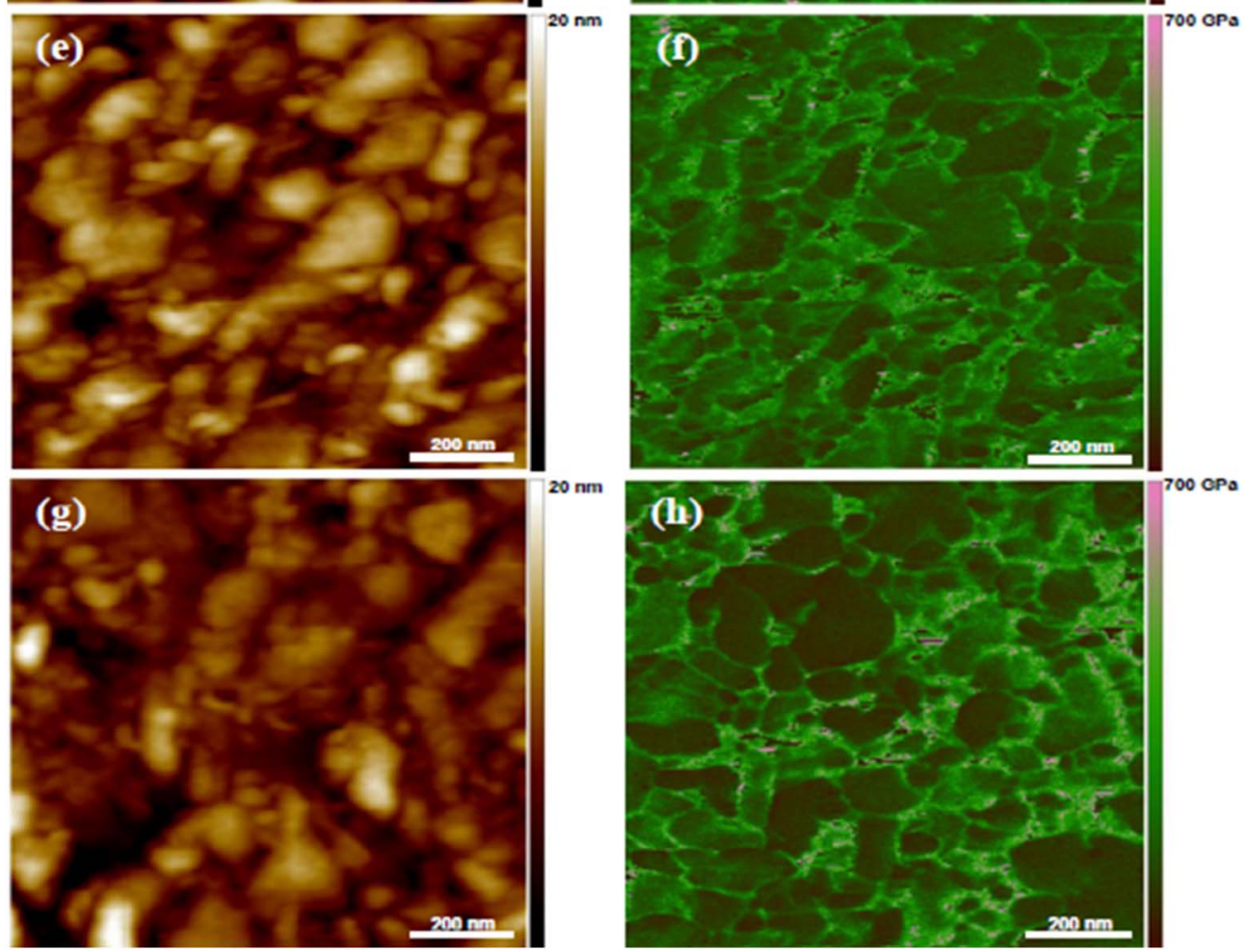

Mo $=1.05$ ) the stress state remains constant which appears to be related to the increase of the crystalline size and to the progressive appearance of $\zeta$-MoN. At N/Mo ratio of 1.1 a value of $-290 \mathrm{MPa}$ is observed (a sudden increase of about $100 \mathrm{MPa}$ ). The high compressive stresses is generated by a high density of the grain boundaries and defects as reported by Detor [51] and the presence of hexagonal MoN. Sarioglu et al. [47] have reported that residual stresses in the hexagonal MoN films was greater than the residual stresses in cubic $\mathrm{Mo}_{2} \mathrm{~N}$. Following the XRD investigations, it corresponds to the smallest crystallite size and to the coexistence of $\delta$-MoN and $\zeta-\mathrm{MoN}$ phases.

\subsubsection{Hardness and elastic modulus}

In transition metal compounds, the chemical bond and cohesion energy are related to the mechanical properties, like Young's modulus and hardness [39]. Fig. 5(a) displays nanoindentation measurements for the different samples as a function of the depth penetration. The indentation depth of the curve of the Mo-N depends of the nitrogen concentration in the film. The result is in good agreement with the 
variation of the compressive residual stress into the film and the information obtained from the microstructure images. The films at $20 \%$ and $50 \%$ nitrogen concentration in the plasma present high compressive stresses and dense microstructure areas, consequently the penetration of the indenter is lower than in the other films and inhibit crack propagation in the coating, while at $30 \%$ and $40 \%$ nitrogen concentration low compressive stresses and separate columnar areas would facilitate crack propagation and changes in the mechanical properties of the thin films. However, the indentation depth at $40 \%$ and $50 \%$ nitrogen concentration is greater of about $10 \%$ than for the other films and the substrate properties can affect the calculated hardness and elastic modulus of the films. The best way to estimate the hardness of a film is to deposit it on a substrate that has the same elastic modulus as that of the film, but unfortunately this occurs rarely [52]. The measured hardness variation is explained by morphological changes. The extracted values of hardness $\mathrm{H}$ and elastic modulus $\mathrm{E}$ for each film are represented in Fig. 5(b) as a function of the N/Mo atomic ratio. A correlation between the hardness and elastic modulus with the penetration depth is observed. The values of $\mathrm{H}$ and $\mathrm{E}$ lay in the range between 13 and $18 \mathrm{GPa}$, and 198 to $240 \mathrm{GPa}$ respectively, depending on the nitrogen partial pressure in the plasma and N/Mo ratio in the films.

The hardness and elastic modulus measured by nanoindentation, and the predicted values of hardness and elastic modulus are in good agreement with the residual stress values. It is observed that at large compressive stress the values of $\mathrm{H}$ and $\mathrm{E}$ are higher than the values at lower stress state, whereas the penetration of the indenter decreases. These values are smaller than those reported for $\gamma-\mathrm{Mo}_{2} \mathrm{~N}$ coatings deposited on stainless steel substrates (23 GPa and $290 \mathrm{GPa}$ for $\mathrm{H}$ and $\mathrm{E}$ respectively) [43] or a hardness of $33 \mathrm{GPa}$ reported for sputtered cubic $\mathrm{MoN}_{0.53}[42,53]$. We can explain this by the changes in the bonding energy in the films when the nitrogen concentration increases. For bulk $\gamma-\mathrm{Mo}_{2} \mathrm{~N}$, a hardness value of $17 \mathrm{GPa}$ is reported in literature $[54,55]$.

The increase of the grain size when the nitrogen partial pressure increases from $20 \%$ to $40 \%$, is followed by a decreasing hardness. Sundgren [1] has reported that the microstructure is of great importance for the physical properties of TiN thin films. The microstructure strongly influences the hardness and the stress values of Mo-N compounds. Hones et al. have reported that the hardness of molybdenum nitride films decreases with an increasing nitrogen content in the fcc $\gamma-\mathrm{Mo}_{2} \mathrm{~N}$ structure [55]. So the significant increase of hardness and elastic modulus observed at $1.1 \mathrm{~N} /$ Mo ratio may be related to the coexistence of both hexagonal and cubic MoN structures.

The Mo-N samples were also studied with the Peak-Force QNM imaging mode. Fig. 6 shows the recorded topography and maps of the elastic modulus for the samples. The average roughness (calculated from the height images) was $6,7,33$ and $11 \mathrm{~nm}$ for samples at $20 \%$, $30 \%, 40 \%$ and $50 \%$ nitrogen concentration in plasma respectively. The height images show that the surface topography strongly depends on the $\mathrm{N}_{2}$ ratio in the plasma. The sample at $20 \% \mathrm{~N}_{2}$ appears to be dense Fig. 6(a), where only few and small clusters or grains can be seen at the surface. The size of these clusters or grains seems to increase with an increasing $\mathrm{N}_{2}$ concentration Fig. 6(c) and (e). However, small grains are found at $50 \% \mathrm{~N}_{2}$ concentration, as seen in Fig. $6(\mathrm{~g})$. This behavior or evolution of the grain size with the concentration of $\mathrm{N}_{2}$ was also observed by the XRD (Section 3.1).

The Derjaguin-Müller-Toporov (DMT) fit model was used to calculate elastic moduli using the unloading parts of the force curves. Fig. 6(b, d, f and h) shows the Young's moduli maps of samples. All Mo$\mathrm{N}$ film surfaces films exhibit heterogeneous contrast depending on its compositions. The dark green domains (low modulus) are clusters surface (highest parts of film surface), while the light green domain (high modulus) corresponds to the lowest parts of sample surface. This observation underlines the importance of low surface roughness for the nanomechanical testing of material surfaces. The average values of the DMT elastic modulus of Mo-N samples are shown in Fig. 5(b). The strong variation of the measured moduli presumably comes from the topological roughness and impurities. The values are a factor of 1.2 to 2.3 smaller than the nanoindenter-measured moduli. The value of the elastic modulus of the sample at $20 \% \mathrm{~N}_{2}$ was found to be $190 \pm 50 \mathrm{GPa}$. This value is close to the nanoindenter value ( $\approx 240 \mathrm{GPa}$ ) but still seems to be underestimated. The difference between AFM and nanoindenter moduli values can be attributed to the loading force used. For the AFM measurements, the loading force is about $200 \mathrm{nN}$, thus the probe depth penetration $(\approx 3 \mathrm{~nm})$ is smaller than the one used in nanoindenter analysis $5 \mathrm{mN}$ and $140 \mathrm{~nm}$ respectively. In addition, since the AFM probes used in this work are specified by the manufacturer to cover the range from 10 to $100 \mathrm{GPa}$, moduli exceeding $100 \mathrm{GPa}$ are maybe underestimated [56], although sufficient deformation was achieved. Nevertheless, even if there is a difference between the modulus values measured by AFM and nanoindenter, the elastic modulus behavior as a function of the concentration of the $\mathrm{N}_{2}$ added in the plasma phase remains the same in both cases. Indeed, the AFM modulus decreases with increasing $\mathrm{N}_{2}$ concentration until $40 \%$ and then increases for $50 \%$ of $\mathrm{N}_{2}$ in the plasma.

\section{Conclusion}

In this study we have investigated the microstructure, residual stress and mechanical properties of molybdenum nitride deposited by reactive R.F. magnetron sputtering. The face centered cubic (fcc) $\gamma-\mathrm{Mo}_{2} \mathrm{~N}$ phase was the only phase presented in the range from $20 \%$ to $40 \%$ nitrogen in the plasma while, at high nitrogen content $(50 \%)$ in the plasma the coexistence of hexagonal and cubic MoN phases were observed. The significant increase of the compressive stress and the changes in the mechanical properties (hardness and elastic modulus) observed at $50 \%$ nitrogen concentration in the plasma may be related to the observed change of structure from $\gamma-\mathrm{Mo}_{2} \mathrm{~N}$ to $\delta$-MoN and B1-MoN; this needs to be further investigated. A clear correlation between microstructure, residual stress and mechanical properties of the films was found to exist.

\section{References}

[1] J.E. Sundgren, Structure and properties of TiN coatings, Thin Solid Films 128 (1985) 21-44 (1985/06/14).

[2] Y.L. Chipatecua, J.J. Olaya, D.F. Arias, Corrosion behaviour of CrN/Cr multilayers on stainless steel deposited by unbalanced magnetron sputtering, Vacuum 86 (2012) 1393-1401.

[3] Q. Wang, F. Zhou, C. Wang, M.-F. Yuen, M. Wang, T. Qian, M. Matsumoto, J. Yan, Comparison of tribological and electrochemical properties of TiN, CrN, TiAlN and aC:H coatings in simulated body fluid, Mater. Chem. Phys. 158 (2015) 74-81.

[4] D. Craciun, N. Stefan, G. Socol, G. Dorcioman, E. McCumiskey, M. Hanna, C. Taylor, G. Bourne, E. Lambers, K. Siebein, Very hard TiN thin films grown by pulsed laser deposition, Appl. Surf. Sci. 260 (2012) 2-6.

[5] T. Fu, X. Peng, Y. Zhao, R. Sun, S. Weng, C. Feng, Z. Wang, Molecular dynamics simulation of TiN (001) thin films under indentation, Ceram. Int. 41 (2015) 14078-14086.

[6] M.K. Kazmanli, M. Ürgen, A.F. Cakir, Effect of nitrogen pressure, bias voltage and substrate temperature on the phase structure of Mo-N coatings produced by cathodic arc PVD, Surf. Coat. Technol. 167 (2003) 77-82.

[7] J. Valli, U. Mäkelä, H. Hentzell, Tribological properties of $\mathrm{MoN}_{\mathrm{x}}$ coatings in contact with copper, J. Vac. Sci. Technol. A 4 (1986) 2850-2854.

[8] V. Anitha, A. Bhattacharya, N.G. Patil, S. Major, Study of sputtered molybdenum nitride as a diffusion barrier, Thin Solid Films 236 (1993) 306-310.

[9] I. Jauberteau, A. Bessaudou, R. Mayet, J. Cornette, J. Jauberteau, P. Carles, T. Merle-Méjean, Molybdenum nitride films: crystal structures, synthesis, mechanical, electrical and some other properties, Coatings 5 (2015) 656-687.

[10] S. Wang, D. Antonio, X. Yu, J. Zhang, A.L. Cornelius, D. He, Y. Zhao, The hardest superconducting metal nitride, Sci Rep (2015) 5.

[11] A.Y. Ganin, L. Kienle, G.V. Vajenine, Synthesis and characterisation of hexagonal molybdenum nitrides, J. Solid State Chem. 179 (2006) 2339-2348.

[12] Y. Miyagawa, S. Nakao, K. Baba, M. Ikeyama, K. Saitoh, S. Miyagawa, Nitride layers formed by nitrogen implantation into metals, Mater. Sci. Eng. A 253 (1998) $135-142$.

[13] H. Jehn, P. Ettmayer, The molybdenum-nitrogen phase diagram, J. Less-Common Met. 58 (1978) 85-98.

[14] A.I. Gusev, A.A. Rempel, A.J. Magerl, Disorder and Order in Strongly Nonstoichiometric Compounds: Transition Metal Carbides, Nitrides and Oxides, vol. 47, Springer Science \& Business Media, 2013.

[15] A. Gilewicz, B. Warcholinski, D. Murzynski, The properties of molybdenum nitride 
coatings obtained by cathodic arc evaporation, Surf. Coat. Technol. 236 (2013) 149-158.

[16] H. Ihara, N. Terada, K. Senzaki, M. Hirabayashi, Y. Kimura, R. Uzuka, F. Kawashima, M. Akimoto, H. Kezuka, Synthesis of MoN and RuN by active nitrogen sputtering, IEEE Trans. Magn. 23 (1987) 1011-1013.

[17] H. Thara, K. Senzaki, Y. Kimura, M. Hirabayashi, N. Terada, H. Kezuka, High-Tc MoN thin film synthesis, Advances in Cryogenic Engineering Materials, Springer, 1986, pp. 603-616.

[18] S. Mändl, D. Manova, J. Gerlach, W. Assmann, H. Neumann, B. Rauschenbach, High temperature nitrogen plasma immersion ion implantation into molybdenum, Surf. Coat. Technol. 180 (2004) 362-366.

[19] P.J. Rudnik, M.E. Graham, W.D. Sproul, High rate reactive sputtering of $\mathrm{MoN}_{\mathrm{x}}$ coatings, Surf. Coat. Technol. 49 (1991) 293-297.

[20] D. Papaconstantopoulos, W. Pickett, B. Klein, L. Boyer, Electronic properties of transition-metal nitrides: the group-V and group-VI nitrides $\mathrm{VN}, \mathrm{NbN}, \mathrm{TaN}, \mathrm{CrN}$, MoN, and WN, Phys. Rev. B 31 (1985) 752.

[21] M. Griepentrog, G. Krämer, B. Cappella, Comparison of nanoindentation and AFM methods for the determination of mechanical properties of polymers, Polym. Test. 32 (2013) 455-460.

[22] B. Bouaouina, A. Besnard, S. Abaidia, F. Haid, Residual stress, mechanical and microstructure properties of multilayer Mo $2 \mathrm{~N} / \mathrm{CrN}$ coating produced by RF Magnetron discharge, Appl. Surf. Sci. 395 (2017) 117-121.

[23] J.E. Sader, I. Larson, P. Mulvaney, L.R. White, Method for the calibration of atomic force microscope cantilevers, Rev. Sci. Instrum. 66 (1995) 3789-3798.

[24] A. Gilewicz, R. Jedrzejewski, A.E. Kochmanska, B. Warcholinski, Structure of MoCN films deposited by cathodic arc evaporation, Thin Solid Films 577 (2015) 94-96.

[25] V.P. Anitha, S. Major, D. Chandrashekharam, M. Bhatnagar, Deposition of molybdenum nitride thin films by r.f. reactive magnetron sputtering, Surf. Coat. Technol. 79 (1996) 50-54.

[26] N. Terada, M. Naoe, Y. Hoshi, Synthesis of B1 MoN films by ion beam deposition, Advances in Cryogenic Engineering Materials, Springer, 1986, pp. 663-670.

[27] A.J. Perry, A.W. Baouchi, J.H. Petersen, S.D. Pozder, Crystal structure of molybdenum nitride films made by reactive cathodic arc evaporation, Surf. Coat. Technol. 54-55 (Part 1) (1992) 261-265.

[28] G. Linker, H. Schmidt, C. Politis, R. Smithey, P. Ziemann, Magnetic susceptibility and defect structure of B1 phase MoN sputtered films, J. Phys. F 16 (1986) 2167.

[29] G.L. Hart, B.M. Klein, Phonon and elastic instabilities in MoC and MoN, Phys. Rev. B 61 (2000) 3151

[30] N. Koutná, D. Holec, O. Svoboda, F.F. Klimashin, P.H. Mayrhofer, Point defects stabilise cubic Mo-N and Ta-N, J. Phys. D. Appl. Phys. 49 (2016) 375303.

[31] B. Ozsdolay, K. Balasubramanian, D. Gall, Cation and anion vacancies in cubic molybdenum nitride, J. Alloys Compd. 705 (2017) 631-637.

[32] E. Donovan, G. Hubler, M. Mudholkar, L. Thompson, Ion-beam-assisted deposition of molybdenum nitride films, Surf. Coat. Technol. 66 (1994) 499-504.

[33] K. Inumaru, K. Baba, S. Yamanaka, Structural distortion and suppression of superconductivity in stoichiometric B $1-$ MoN epitaxial thin films, Phys. Rev. B 73 (2006) 052504.

[34] L. Stöber, J.P. Konrath, S. Krivec, F. Patocka, S. Schwarz, A. Bittner, M. Schneider, U. Schmid, Impact of sputter deposition parameters on molybdenum nitride thin film properties, J. Micromech. Microeng. 25 (2015) 074001.

[35] K. Saito, Y. Asada, Superconductivity and structural changes of nitrogen-ion implanted Mo thin films, J. Phys. F 17 (1987) 2273.

[36] M. Urgen, O.L. Eryilmaz, A.F. çakir, E.S. Kayali, B. Nilufer, Y. Isik, Characterization of molybdenum nitride coatings produced by arc-PVD technique, Surf. Coat.
Technol. 94-95 (1997) 501-506.

[37] J. Barbosa, L. Cunha, L. Rebouta, C. Moura, F. Vaz, S. Carvalho, E. Alves, E. Le Bourhis, P. Goudeau, J.P. Rivière, Properties of $\mathrm{MoN}_{\mathrm{x}} \mathrm{O}_{\mathrm{y}}$ thin films as a function of the N/O ratio, Thin Solid Films 494 (2006) 201-206.

[38] Y. Wang, R.Y. Lin, Amorphous molybdenum nitride thin films prepared by reactive sputter deposition, Mater. Sci. Eng. B 112 (2004) 42-49.

[39] F. Levy, P. Hones, P.E. Schmid, R. Sanjines, M. Diserens, C. Wiemer, Electronic states and mechanical properties in transition metal nitrides, Surf. Coat. Technol. 120-121 (1999) 284-290.

[40] R.R. Krishnan, R.S. Sreedharan, S.K. Sudheer, C. Sudarsanakumar, V. Ganesan, P. Srinivasan, V.P.M. Pillai, Effect of tantalum doping on the structural and optical properties of RF magnetron sputtered indium oxide thin films, Mater. Sci. Semicond. Process. 37 (2015) 112-122.

[41] P. Hones, R. Sanjines, F. Lévy, Characterisation of sputter-deposited chromium nitride thin films for hard coatings, Surf. Coat. Technol. 94-95 (1997) 398-402.

[42] F. Klimashin, N. Koutná, H. Euchner, D. Holec, P. Mayrhofer, The impact of nitrogen content and vacancies on structure and mechanical properties of Mo-N thin films, J. Appl. Phys. 120 (2016) 185301.

[43] V.P. Anitha, S. Vitta, S. Major, Structure and properties of reactively sputtered $\mathrm{Mo}_{2} \mathrm{~N}$ hard coatings, Thin Solid Films 245 (1994) 1-3.

[44] A. Besnard, N. Martin, C. Millot, J. Gavoille, R. Salut, Effect of sputtering pressure on some properties of chromium thin films obliquely deposited, IOP Conference Series: Materials Science and Engineering, 12 2010, p. 012015.

[45] D. Depla, R. De Gryse, Target poisoning during reactive magnetron sputtering: part I: the influence of ion implantation, Surf. Coat. Technol. 183 (2004) 184-189.

[46] D. Depla, R. De Gryse, Target poisoning during reactive magnetron sputtering: part II: the influence of chemisorption and gettering, Surf. Coat. Technol. 183 (2004) 190-195.

[47] C. Sarioglu, U. Demirler, M.K. Kazmanli, M. Urgen, Measurement of residual stresses by X-ray diffraction techniques in $\mathrm{MoN}$ and $\mathrm{Mo}_{2} \mathrm{~N}$ coatings deposited by arc PVD on high-speed steel substrate, Surf. Coat. Technol. 190 (2005) 238-243.

[48] H.J. Wang, H.A. Deng, S.Y. Chiang, Y.F. Su, K.N. Chiang, Development of a process modeling for residual stress assessment of multilayer thin film structure, Thin Solid Films 584 (2015) 146-153.

[49] G. Kleer, R. Kassner, E.M. Meyer, M.G. Schinker, W. Doell, Effect of process parameters on the residual stresses and the war behavior of aluminum nitride physical vapor deposition coatings, Surf. Coat. Technol. 54 (55) (1992) 167-172.

[50] M.R. Ardigo, M. Ahmed, A. Besnard, Stoney formula: investigation of curvature measurements by optical profilometer, Adv. Mater. Res. 966 (2014) 361-366.

[51] A.J. Detor, A.M. Hodge, E. Chason, Y. Wang, H. Xu, M. Conyers, A. Nikroo, A. Hamza, Stress and microstructure evolution in thick sputtered films, Acta Mater. 57 (2009) 2055-2065.

[52] R. Saha, W.D. Nix, Effects of the substrate on the determination of thin film mechanical properties by nanoindentation, Acta Mater. 50 (2002) 23-38.

[53] F. Klimashin, H. Euchner, P. Mayrhofer, Computational and experimental studies on structure and mechanical properties of Mo-Al-N, Acta Mater. 107 (2016) 273-278.

[54] S.T. Oyama, Crystal structure and chemical reactivity of transition metal carbides and nitrides, J. Solid State Chem. 96 (1992) 442-445.

[55] P. Hones, N. Martin, M. Regula, F. Lévy, Structural and mechanical properties of chromium nitride, molybdenum nitride, and tungsten nitride thin films, J. Phys. D. Appl. Phys. 36 (2003) 1023.

[56] J. Adamcik, A. Berquand, R. Mezzenga, Single-step direct measurement of amyloid fibrils stiffness by peak force quantitative nanomechanical atomic force microscopy, Appl. Phys. Lett. 98 (2011) 193701. 